\title{
Using global environment trends for adaptating the higher education to changes and increasing the investment attractiveness of the region
}

\author{
Nadezhda Kaluzhnova ${ }^{1, *}$, Elena Ogarkova ${ }^{1}$, and Mikhail Osipov ${ }^{1}$ \\ ${ }^{1}$ Irkutsk State University, 664003, Karla Marksa str., 1, Irkutsk, Russia
}

\begin{abstract}
The work is devoted to the analysis of the possibilities of adaptation of the Russian system of higher education to changing global environment. The main trends of these changes are singled out and characterized. The results of a sociological study of the correspondence of the existing organizational structures of higher education institutions to the needs of students and the requirements of the time are presented. Measures to improve the system of university training with the aim of forming a modern and adaptive organizational structure are proposed in the paper.
\end{abstract}

The complex of infrastructure factors (social, production and technological infrastructure) significantly influences the investment attractiveness of the region. Social infrastructure, which implies the availability and quality of housing, education, health, culture, and sports, plays a special role in this complex. As noted by V. Miakshin, social infrastructure is an important factor determining the direction of migration of economically active population, and the state of labor potential [1]. Interest in investing in the region, especially in real estate, directly depends on the demand for this property, which, in turn, is also determined by the quantity and quality of the economically active population in the region. The higher school provides the real estate markets with human resources, and scientific and innovative basis. The level of innovativeness of the system of higher education makes it possible to form human capital taking into account the interests of the region, on the one hand, and provides the scientific content of innovations in various fields. For this reason, we consider it important to focus on how the higher education system adapts to the changes of environment and how global trends are taken into account.

Having once started his movement in the direction of improving the diverse processes that ensure the convenience of producing the essential goods, a person never stops at what has been achieved. Moreover, this movement is accelerating every year and requires participants to adapt quickly to changes. In these conditions, the person is, on the one hand, the initiator of changes, and, on the other hand, he himself is forced to constantly adapt to them in absolutely all spheres of his life.

The labor activity, which manifests itself in the main two forms, wage labor or entrepreneurial activity, is the most important sphere of a person's life. Higher school is an institution the most important function of which is a preparation for work. This training

*Corresponding author: 2010nyk@ mail.ru 
should take into account the trends that take place in the global environment, so that the institutions of higher education not only kept up, but also anticipated the future transformations of labor activity.

Let us consider what trends of the global environment must be taken into account and how to neutralize the negative challenges of the macro-environment in order to be a competitive form of education. First of all, we will differentiate the environment into a global, macro- and micro-environment: the global one encompasses all factors, processes and phenomena at a global, world-wide level; macro-environment is a set of economic, political, cultural, socio-demographic and other factors in the country that do not depend on the educational institution, but seriously affect its activities; micro-environment represents the level of a separate educational institution or group of educational institutions.

One of the main features of the modern global environment is that today the nature of labor activity is being transformed. M. Castells identifies two types of labor: a generic and self-programmed, that is, a highly specialized work rigidly connected with a certain type of production. Generic labor refers to a specific task, does not have the ability to reprogram, and does not contain information and knowledge beyond the ability to receive and execute signals [2]. The difference between generic and self-programmed work was revealed by E. Toffler, who metaphorically compared them with classical and jazz musicians. If the first ones play each note written in the score, the second, deciding which melody to perform, pick up each other's signals and freely improvise [3]. Self-programmed work is the result of the development of the personality as a specialist whose education and mentality require a continuous self-feeding of knowledge and meanings. It is a new type of employee who refers to work as a way of realizing his abilities, which he constantly cultivates through education. Generic labor involves a narrow specialization. Undoubtedly, the narrower is the specialization of a person, the more competent he is in this field, and professionalism of such a person is beyond doubt. But these are highly specialized specialists in the staff of the company that become an exorbitant burden - it is difficult to provide flexibility in a changing environment in order to adapt to various kinds of changes. This is the situation that is now developing in the education system.

The second trend is the constant changes in the environment of the labor market, which must be quickly adapted, offering new and demanded educational products. This process is especially accelerated in connection with the development of automation, artificial intelligence, blockchain technologies, online businesses, which will increasingly release workers from traditional spheres of employment, associated with various repetitive operating activities (clerks in different institutions, operators, etc.).

The third trend touches upon the development of competition from other various institutions offering knowledge. These are off-line courses, on-line courses - a direction called info-business, distance learning, such as Coursera, Netology, courses of different US and other universities. These mobile forms of education challenge traditional diplomas of higher education, because they give a highly relevant training in a short time. Often, these forms do not provide the necessary quality, because they do not have standards, teaching methods, and to some extent they do damages, diverting time and money of those who want to gain new knowledge and skills.

Trends in the micro-sphere also contain negative challenges. There is an intensification of the bureaucratization of educational processes at all levels. This is not least influenced by the introduction of the Unified State Exams (USE) in the field of general secondary education, and the introduction of professional standards, which should be guided by employers when hiring employees. The USE makes teachers restrict themselves to learning only didactic units indicated in the educational standards, and also to teach strategies and templates for the passing of the USE. 
The introduction of professional standards, in turn, leads to the fact that specialized secondary and higher education is forced to adjust its activities to narrowly defined competencies, which can be mastered within a certain direction of training. Thus, the learning process at all levels is rigidly regulated and bureaucratized. In such conditions, only private structures that carry out their activities on the market basis have the opportunity to adapt to the labor market changes. But private structures allow providing only a narrow specialized development of a single competence. Schools and institutions of secondary vocational education and higher education have other functions: comprehensive development of a personality, capable of adapting to any environment that can be mobile in any situation.

Thus, at the moment we have two differently directed processes that reduce the effectiveness of adaptation of educational institutions to the challenges of the macroenvironment. Constant changes of the conjuncture in the labor market make it necessary to train specialists who are able to self-program their work. But the education system is increasingly focused on training of narrow specialists. In order that educational institutions of all levels can quickly and adequately adapt to changes in the macro-environment, it is necessary to ensure flexibility of these processes in the institution.

For the analysis, we propose two hypotheses. The first hypothesis contains the statement that the existing system of training in a typical institution does not meet the requirements of the time and the needs of students. The second hypothesis is that the existing organizational structure does not allow providing sufficient answers to those challenges that were listed earlier.

The study of hypotheses will be considered on the example of economic education in the higher education establishment. In many universities of the country there is a situation when the disciplines of the social and humanitarian block are gradually being removed from the curricula, since each faculty is interested in preserving the work load for their "own" teachers. At the same time, students need to be prepared not only for work in their profession or specialty, but also master the skills of commercializing their professional knowledge that corresponds to the trends referred in the beginning of this article.

To verify this situation, in March, 2018, in the framework of the Laboratory of Social and Economic Research at the Department of Economic Theory and Management of Irkutsk State University (ISU) we conducted a research "The relevance of economic education for the ISU students". The purpose of the study was to determine the requests of students, primarily of the faculties of natural sciences of ISU, for additional economic education. The research tasks were to determine the requirements of students for the educational products in the field of economics and management - training options, load, cost, and curricula.

The sample is based on the Nürburg method (available sample). There are 281 people $3.67 \%$ of the general totality, which for this project is defined in 7,582 full-time students of 13 faculties, which have no economic departments. With a sample of 204-400 people for the general totality of 4,000 to 10,000 people, the actual error of the survey results will be $5-7 \%$ [4]. Thus, the survey is representative with an average error of $6 \%$, which gave grounds to extend its results to the whole general totality and to calculate the possible demand for additional economic education of the ISU students.

Unequivocally, $43.5 \%$ of students experience the need for economic knowledge, and $30.8 \%$ of students do not feel so. At the same time, $35.4 \%$ want to pursue entrepreneurial activity after the university, $58.5 \%$ want to open their own enterprise, almost $45 \%$ would like to have an annex to the diploma with economic disciplines, plus it is necessary to add to these data 30 to $40 \%$ of those who are not sure in the answer but can believe that such knowledge is needed. At the same time, almost everyone proceeds answering the questions of the questionnaire and chooses the disciplines that he/ she would like to study. The distribution of answers is shown in Figure 1. 


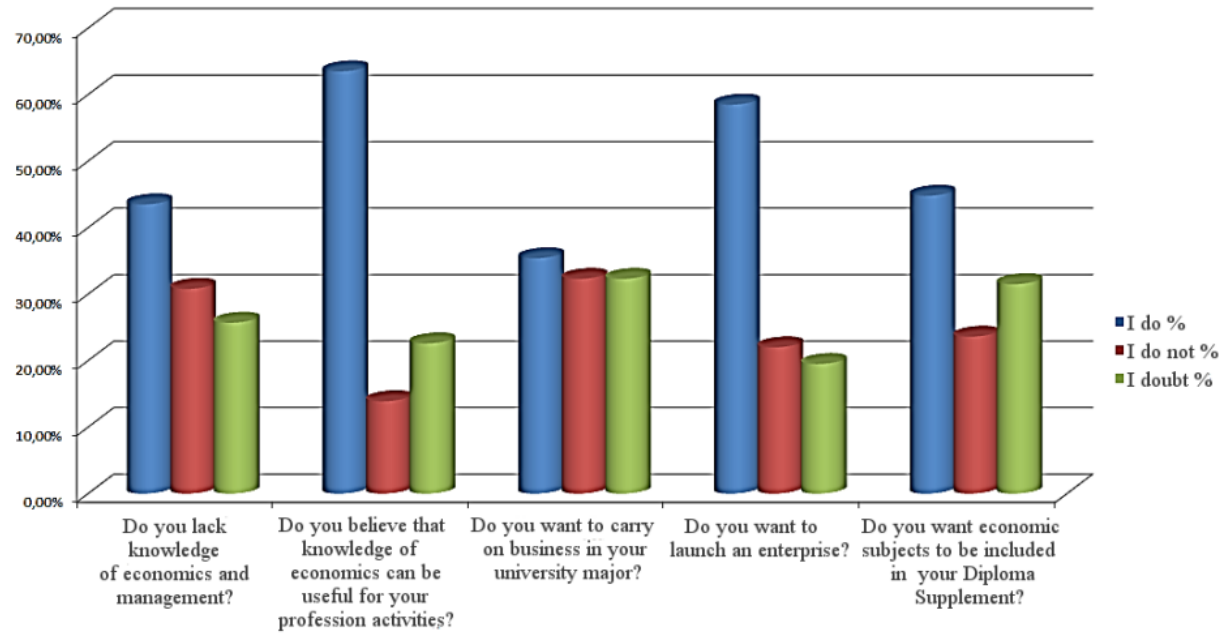

Fig. 1. The need for economic knowledge and entrepreneurial skills.

All educational products were allocated into the following categories: elective disciplines ( 30 and 45 hours), which can be studied, and a certificate (30 hours) or inclusion in the annex to the diploma (45 hours) can be obtained; advanced training (72 and 144 hours); and vocational training ( 250 hours). Of the offered options, preferences are given to the advanced training courses (44\%) and elective courses with entries into the annex to the Bachelor's Diploma (30\%). Some students are ready to pass elective courses with a certificate. It should be noted that more than half of the students want the studied disciplines in the field of economics and management to be included in the list of the passed disciplines in the annex to the Bachelor's Diploma (30\%). Preferences on the forms of obtaining additional economic education are reflected in Figure 2.

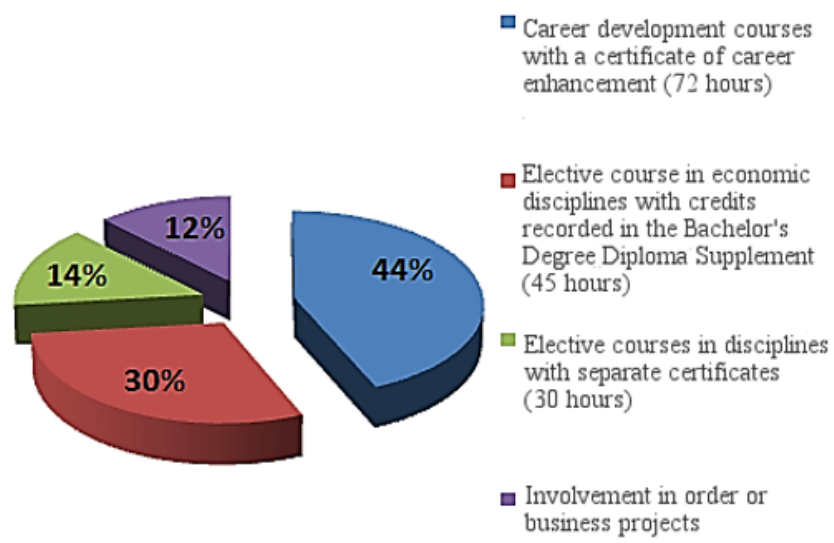

Fig. 2. Preferences on forms of obtaining additional economic education.

Three training programs were proposed, the distribution of the responses among which is shown in the Figure 3. 


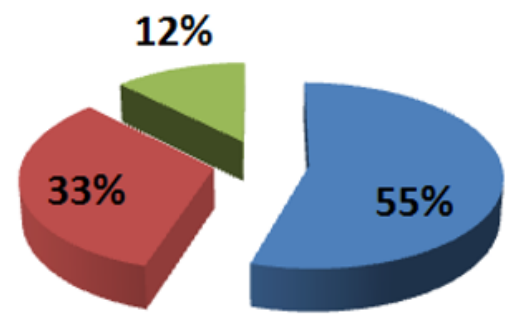

Economics and small and medium- size business management

Modern marketing

Application of block- chain technology in economics

Fig. 3. Selected training programs.

Most students $(77 \%)$ are willing to devote more than two academic hours a week to additional classes. Since the time devoted to the classroom activities is limited, we had the assumption that students would choose a distance learning form, or classroom classes with elements of distance learning. But, nevertheless, students prefer to study additional disciplines in the field of economics and management in the traditional form - as a lecture work with the teacher ( $64 \%$ of respondents). $28 \%$ of respondents are ready to combine the work in the classroom with elements of distance learning. Despite a small percentage of respondents who prefer distance forms of education (8\%), this way of working cannot be ruled out either.

For the study of price preferences, we proposed a scheme, which presumes the possibility of paying with subscriptions from 1 lecture (1.5 hours) to the blocks of different duration (6 hours, 15 hours), and the course as a whole. And, the price depends on the time of payment - in advance of the beginning of the academic year the price is the lowest, one week before classes - it is higher, and the highest one - just a day before the beginning of classes. The distribution of respondents' answers is shown in the Table 1.

Table 1. Selection of the form of payment.

\begin{tabular}{|l|c|c|c|c|c|c|}
\hline & \multicolumn{2}{|c|}{$\begin{array}{c}\text { In advance of } \\
\text { the beginning of } \\
\text { the academic } \\
\text { year }\end{array}$} & \multicolumn{2}{|c|}{$\begin{array}{c}\text { One week before } \\
\text { classes }\end{array}$} & \multicolumn{2}{|c|}{$\begin{array}{c}\text { A day before the } \\
\text { beginning of } \\
\text { classes }\end{array}$} \\
\cline { 2 - 7 } & Rubles & $\begin{array}{c}\text { Selected } \\
\%\end{array}$ & Rubles & $\begin{array}{c}\text { Selected } \\
\%\end{array}$ & $\begin{array}{c}\text { Ruble } \\
\text { s }\end{array}$ & $\begin{array}{c}\text { Selected } \\
\%\end{array}$ \\
\hline $\begin{array}{l}\text { Subscriptions for 1 lecture (1.5 } \\
\text { hours) }\end{array}$ & 150 & 40 & 250 & 12 & 300 & 6 \\
\hline $\begin{array}{l}\text { Subscriptions for 4 lectures (6 } \\
\text { hours) }\end{array}$ & 550 & 29 & 900 & 7 & 1800 & 2 \\
\hline $\begin{array}{l}\text { Subscriptions for 10 lectures (15 } \\
\text { hours) }\end{array}$ & 1400 & 31 & 2500 & 6 & 3000 & 5 \\
\hline $\begin{array}{l}\text { Payment for the one discipline } \\
\text { with a certificate (30 hours) }\end{array}$ & 2700 & 38 & 4500 & 6 & 5400 & 3 \\
\hline $\begin{array}{l}\text { Payment for the whole training } \\
\text { course on one discipline, with an } \\
\text { annex to diploma (45 hours) }\end{array}$ & 4100 & 39 & 6900 & 7 & 8400 & 3 \\
\hline $\begin{array}{l}\text { Payment for training courses } \\
\text { (several disciplines, 72 hours) }\end{array}$ & 6500 & 47 & 11000 & 5 & 13800 & 1 \\
\hline
\end{tabular}


Such a proposal has been made to enable students to choose payment options, options for training trajectories, and to study the possibility of tokenization of additional economic education, as it will be described below. In the future, the students will have the opportunity to implement an individual trajectory of learning by selecting a number of classes (or tokens) for themselves to obtain certificates or an entry to the annexes to the diploma. The students are still unaccustomed to this choice, and during a short survey time it is difficult for them to compare the options thoroughly. Nevertheless, according to the results of the Table, one can judge the popularity of the options. The result showed that students prefer to save, and from 29 to $46 \%$ of them choose to pay in advance for a lower price. From 4.6 to $11.9 \%$ of students preferred a higher payment a week before the beginning of the classes. From 1.4 to $13 \%$ chose to pay the day before the beginning of the classes.

In general, our assumption that students will prefer a lower payment in advance was justified. The most frequent choice is a payment for the whole training course in advance at a price of 6500 rubles $-46.8 \%$. Payment for the course of lectures on one discipline with the receipt of a certificate ( 30 hours) at a price of 2700 rubles has been chosen by $38.1 \%$ of the students. Payment for the whole course of lectures on one discipline with the annex to diploma (45 hours) at a price of 4100 rubles has been chosen by $39.0 \%$ of the respondents. Payment for professional retraining courses worth 22 thousand rubles and 20 thousand rubles has been selected by 35.2 to $44.7 \%$ of the respondents. Also, the students often chose to pay a subscription for 1 lesson (1 lesson - 1.5 hours) for 150 rubles - 39.9\%.

The popularity of the selected disciplines, which can be listened to by individual courses, is given in the Table 2 .

Table 2. Popularity of the selected disciplines.

\begin{tabular}{|l|c|c|c|c|}
\hline Discipline & $\begin{array}{c}\text { Want to } \\
\text { enroll (\%) }\end{array}$ & $\begin{array}{c}\text { Rank on } \\
\text { those who } \\
\text { want to } \\
\text { enroll }\end{array}$ & $\begin{array}{c}\text { Want to } \\
\text { learn, } \\
\text { people }\end{array}$ & $\begin{array}{c}\text { Rank on } \\
\text { those } \\
\text { who } \\
\text { want to } \\
\text { learn }\end{array}$ \\
\hline Economics & 21.6 & 7 & 65 & 10 \\
\hline Economics of entrepreneurship & 28.3 & 5 & 94 & 3 \\
\hline Social entrepreneurship & 11.8 & 9 & 40 & 12 \\
\hline Creation of enterprise & 29.0 & 3 & 99 & 2 \\
\hline Management & 28.4 & 4 & 71 & 9 \\
\hline Business planning & 35.9 & 1 & 101 & 1 \\
\hline Project management & 29.0 & 2 & 85 & 6 \\
\hline Digital economics & 7.6 & 11 & 26 & 14 \\
\hline $\begin{array}{l}\text { The blockchain and cryptocurrency: an } \\
\text { introductory course }\end{array}$ & 16.4 & 8 & 52 & 11 \\
\hline $\begin{array}{l}\text { Foresight technologies of work with the } \\
\text { future }\end{array}$ & 10.1 & 10 & 33 & 13 \\
\hline $\begin{array}{l}\text { The financial management of the } \\
\text { enterprise }\end{array}$ & 25.9 & 6 & 82 & 8 \\
\hline Basics of modern marketing & 25.9 & 6 & 80 & 7 \\
\hline Personal finance management & 5.2 & 11 & 88 & 5 \\
\hline
\end{tabular}

The results show that the students choose practical disciplines - first of all, business planning, enterprise creation, project management, financial management and modern marketing. But other disciplines also generate interest, including blockchain and cryptocurrencies, and social entrepreneurship. 
The survey showed that from 9.1 to $36.7 \%$ of the students want to go through the training courses, and most of all they pay attention to the training courses in economics and management in the field of small business, and modern marketing. Also from 27.4 to $42.7 \%$ of the students want to get a Diploma of professional retraining in these areas. Thus, less than a third of the students are clearly not motivated for additional education in the field of economics and management.

Those students who do not express full confidence in the need for additional education in the sphere of economics and management, nevertheless, in the course of the survey demonstrated interest in elective disciplines, in additional training, and in professional retraining.

Most students choose to pay in advance with lower prices. The students are almost equally willing to pay for individual lectures, blocks of lectures or the course as a whole that suggests for the possibility of varying prices and payment terms. Those who did not pay in advance, does not mean that he/ she would not pay just before the courses, and it should be kept in mind.

The students are significantly focused on the commercialization of their knowledge, so they choose practical courses, such as "Economics and Management of Small and Medium Business" and "Modern Marketing".

So, the survey showed that more than $70 \%$ of the students demonstrated interest in learning economic disciplines, as well as the desire to master additional economic courses that are not part of the curriculum. In order to provide the existing demand with an adequate supply, it is necessary to attract more specialists in different fields. Let us consider how this is possible.

The organizational structure of higher education institutions is defined by the Law of the Russian Federation "On Education" [6], the Federal Law "On Higher and Post-Graduate Professional Education" [7] and the Model Regulations on the Educational Institution of Higher Professional Education (Higher Education Establishment) [8]. The traditional organization of a university, which was delivered to the Russian higher school as an inheritance from the Soviet period, can be described as divisional. Thus, we face the task of integrating new forms of the organizational relations into the divisional organizational structure of educational institutions. In the conditions of the existing system of department training when it is required to keep a certain minimum number of the staff for the preservation of departments, we have to, first of all, solve the problem of the workload for the full-time teachers.

At the same time, a rapid update of curricula, including magistracy, and the programs of additional training for the students is now required. It means that there is a need to maneuver with the teaching staff. Constant preservation of the same composition leads to the fact that new courses should be developed by the same teachers that does not always provide the necessary professionalization. In addition, it gives a great deal of actual workload for teachers to develop new courses, without increasing the teaching hours. In fact, this leads to the conservation of the developed courses, that is, the organizational structure makes the teaching system to be harsh and conservative. It is necessary to adapt organizational management structures to constantly changing environment.

But, since demands will always be characterized by a change in preferences, maintaining a fixed staff structure will not allow reacting to changes. It turns out that only a new modern structure is capable of ensuring rapid adaptation to changes.

At the end of the $20^{\text {th }}$ and beginning of the $21^{\text {st }}$ century, educational institutions, while formally retaining divisional management structures, increasingly used a matrix type of management, which presupposed the formation of working groups within the framework of research and educational projects. For some time this form of organization of labor was effective. But due to the fact that matrix management still assumes the use of the fixed staff 
units, such a structure cannot provide for a quick and adequate response to the changes in the labor market situation. The concept of formation of the cloud companies are now emerging and being introduced into life [10].

The main features of the cloud companies are the following. 1. Availability of an information system that controls business processes in the enterprise. 2. Constantly changing staff (achieved through the involvement of freelancers and crowdsourcing). 3. Lack of a clear organizational structure (it varies depending on the project and current tasks). Secondary signs: rapid adaptation to the changing market conditions; the use of crowdsourcing; a wide range of types of services in the industry; production of high-intellectual products (the share of intellectual capital prevails) or unique / small-value products; employees of the cloud companies can be in different cities and countries during the production process (geographical redistribution of personnel regardless of the place of production / delivery of the product); innovativeness as a way of life of the company; work on new markets; most of the work is done in groups and on the basis of projects. The organizational structure is based on functional units within the enterprise in the presence of separate units engaged in marketing, finance, and sales of products. The number and type of subdivisions are determined by the nature of the economic activity that the enterprise is engaged in. This allows it realizing the advantages of specialization and the division of labor [11].

The cloud management structures will gradually be introduced into educational institutions of all levels. For example, the composition of specialists of a particular department can be expanded by the process of staff virtualization. That is, most of the employees will carry out their activities solely on a contractual basis on the principles of outsourcing. Each year, it is possible to form inter-faculty groups of students who wish to further master disciplines on a commercial basis (with a significant discount). In addition, it is possible to offer services on the development of economic and social disciplines at the faculties that are oriented towards a specific profile of training, also on a commercial basis. Such a system provides participants with a number of benefits: the faculties will keep a budgetary load for their teachers, students can additionally study a number of disciplines for a small fee, and the departments receive commercial load and money.

As a target audience, it is possible to consider students of other universities, in which curricula there is no economics, but who want to learn the economic disciplines offered by us on their own.

The introduction of the cloud organization into the education system is a promising way to quickly adapt to the changes on the labor market, to changes in preferences among university students and changes in the training load, with a possibility of attracting unique specialists for conducting classes and activating network forms of education.

To ensure the flexibility and choice of students, as well as planning the work of the units on the basis of prepaid training, today one can use such a modern form of granting the right to services as a token.

Token is a digital right to receive a certain service [12]. To a certain extent, token is similar to the provision of season tickets for a class or course. But in this case, the token represents a smaller unit, for example, the right to attend one lesson. Respectively, in order to receive a course, one must buy several tokens that grant the right to complete the whole course. The peculiarity of the token is that it grants the right to the course, but the students can decide which course to choose. The peculiarity is also in the fact that tokens are implemented in advance - before the beginning of the academic year, and herewith they cost less than just before the courses. At the beginning of the courses, the students can choose not only the course and the lecturer, but also decide whether to stay and pass the entire course, or going to one lesson they understand that they do not like it, and then choose another.

Tokens are fixed on one of the blockchain platforms. In fact, it is the issuance of the program code to the students, which is a coin in exchange for paying for courses. The load 
of the department will be composed of all kinds of work and training will become more mobile.

Thus, we will be able to solve the challenge of the education mobility, the formation of economic thinking for all students, the formation of readiness for the commercialization of professional knowledge on the basis of entrepreneurship, and we will use paperless blockchain turnover, while training students to work in the framework of digital economy.

\section{References}

1. V. N. Myakshin, Investment Policy of the Region, 14 (2014)

2. M. Castells, Information age: economics, society and culture (Moscow, 2000)

3. G. A. Barysheva. E. A. Anikina, L. I. Ivankina, E. V. Silifonova, Problems and prospects of accessibility of higher education in the context of modern transformations in Russia (STT, Tomsk, 2016)

4. A. Bogoviz, S. Lobova, Y. Ragulina, A. Alekseev, V. Garnova, MediaobrazovanieMedia Education, 3, 7-14 (2017)

5. N. Ya. Kalyuzhnova, A. Ya. Yakobson, Marketing: general course (Omega-L, 2007)

6. Rossiyskaya Gazeta, On Education: the Law of the Russian Federation of 10.07.1992 No. 3266-1 (Moscow, 2010)

7. Rossiyskaya Gazeta, On Higher and Postgraduate Professional Education: Federal Law of 22.08.1996 No. 125-FZ (Moscow, 2010)

8. Government of Russia, On approval of the Model Provisions on the educational institution of higher professional education (higher educational institution): Resolution of the Government of the Russian Federation No. 71 of 14.02.2008 (Collection of Legislation of the Russian Federation, Moscow, 2008)

9. A. Bogoviz, S. Lobova, Y. Ragulina, A. Alekseev, S. Litvinova, MediaobrazovanieMedia Education, 4, 83-91 (2017)

10. E. P. Ogarkova, Proceedings of the conference "Communication technologies: social and information aspects" (2018)

11. B. Andersen, Business processes: improvement tools (RIA "Standarts and Quality," Moscow, 2003)

12. Projet of the Federal Law "On Amending Part One and Fourth of the Civil Code of the Russian Federation” (https://pravo.ru/news/201311/, 2013) 